\title{
$\mathrm{P}$ \\ аспространенный микоз гладкой кожи \\ с поражением ногтевых пластин стоп, резистентный к противогрибковой терапии
}

Кожичкина Н. В.

Государственный научный центр дерматовенерологии и косметологии

Министерства здравоохранения Российской Федерации

107076, Российская Федерация, г. Москва, ул. Короленко, д. 3, стр. 6

В статье представлены анализ литературы резистентных штаммов к противогрибковым препаратам и описание наблюдения распространенного микоза гладкой кожи с поражением ногтевых пластин стоп, резистентного к противогрибковой терапии, у больного 57 лет. Описывается клиническая картина, диагностика и лечение грибкового заболевания. На фоне противогрибкового лечения достигнуто клиническое и микологическое излечение микоза кожи туловища и ногтей стоп.

Ключевые слова: распространенный микоз, микоз ногтей, резистентность к системной антимикотической терапии

Конфрликт интересов: автор заявляет об отсутствии потенциального конфликта интересов, требующего раскрытия в данной статье.

Для цитирования: Кожичкина Н. В. Распространенный микоз гладкой кожи с поражением ногтевых пластин стоп, резистентный к противогрибковой терапии. Вестник дерматологии и венерологии. 2019;95(6):55-60. https://doi.org/10.25208/0042-4609-2019-95-6-55-60 


\section{istributed glabrous skin mycosis involving foot nail lesions and showing resistance to antifungal therapy}

Natalia V. Kozhichkina

State Research Center of Dermatovenereology and Cosmetology, Ministry of Health of the Russian Federation Korolenko str., 3, bldg 6, Moscow, 107076, Russian Federation

This article presents an analysis of publications on strains resistant to antifungal drugs and describes a clinical case of a 57-year-old patient suffering from distributed glabrous skin mycosis with foot nail lesions resistant to antifungal therapy. The clinical picture, diagnosis and treatment of the fungal disease is described. Against the background of antifungal treatment, the clinical and mycological cure of the trunk skin and foot nail mycosis was achieved.

Keywords: common mycosis, onychomycosis, resistance antifungal therapy

Conflict of interest: the author states that there is no potential conflict of interest requiring disclosure in this article.

For citation: Kozhichkina N. V. Distributed glabrous skin mycosis involving foot nail lesions and showing resistance to antifungal therapy. Vestnik Dermatologii i Venerologii. 2019;95(6):55-60. https://doi.org/10.25208/0042-4609-2019-956-55-60 
Микозы гладкой кожи - довольно часто встречающаяся патология в практики дерматовенеролога. В последнее время отмечается увеличение частоты встречаемости дерматомикозов, резистентных к противогрибковой терапии.

По данным Budak A. и соавт., вне зависимости от возбудителя микоз гладкой кожи встречается в 5,6 \% случаев [1]. Sarifakioglu E. и соавт. отмечают низкую (до $20 \%$ случаев) клиническую эфрфективность терапии при онихомикозе в связи с изменением чувствительности возбудителей к системным антимикотикам [2]. Ряд авторов (Gupta AK и соавт., Mendez-Tovar L. J. и соавт.) выявили резистентность возбудителей дерматомикозов к системным антимикотикам [3, 4].

Bradley M. C. и соавт. связывают неудачи терапии грибковых заболеваний не только с развитием резистентных возбудителей к противогрибковым препаратам, но и с генетической предрасположенностью и персональными факторами, такими как возраст пациента, сопутствующая патология (например, сахарный диабет, псориаз), сосудистые заболевания, иммуносупрессивные заболевания, наличие грибковых заболеваний у родственников, дерматофибромы, в результате которых нарушается кровоснабжение ногтевого ложа [5].

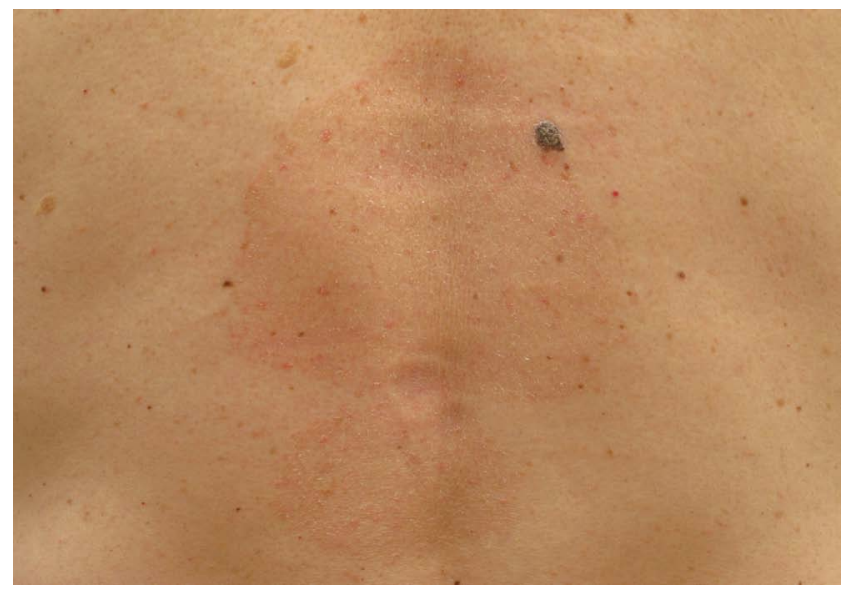

Рис. 1. Состояние кожи спины пациента 57 лет, до начала терапии Fig. 1. The condition of the 57-year-old patient's back skin before therapy

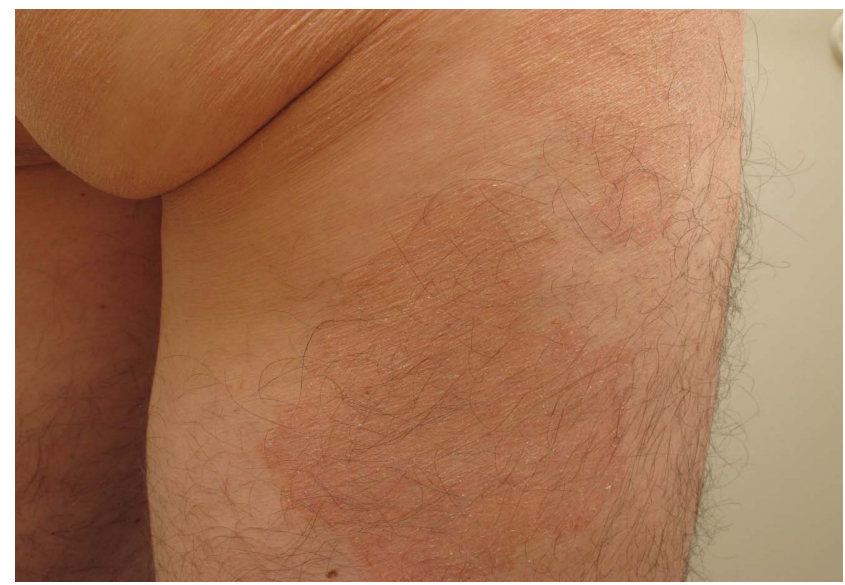

Рис. 3. Состояние кожи правого бедра пациента 57 лет, до начала терапии Fig. 3. The condition of the 57-year-old patient's right thigh skin before therapy
В КДЦ ФГБУ «ГНЦДК» Минздрава России обратился мужчина 57 лет, житель города Москвы, с жалобами на высыпания на коже туловища, конечностей, изменение формы и цвета ногтевых пластин стоп. В анамнезе в течение многих лет изменены ногти стоп, 15 лет назад появились высыпания на коже туловища, которые постепенно распространялись.

Локальный статус: в области спины и боковой поверхности туловища с переходом на правую ягодицу наблюдаются очаги гиперемии с мелкопластинчатым шелушением с четкими границами, возвышающимся валиком по периферии, красного цвета (рис. 1-3). Изменены все ногтевые пластины стоп по гипертрофическому типу, тотальная форма, ногтевое ложе неровное, желтого цвета. На подошвах и боковых поверхностях стоп наблюдается гиперемия и обильное кольцевидное шелушение (рис. 4). Ногтевые пластины кистей не изменены.

Диагностика:

1. При микроскопическом исследовании в лаборатории ГНЦДК МЗ РФ перед началом лечения в соскобе с ногтей стоп и кожи туловища обнаружен мицелий грибов.

2. При культуральном исследовании соскоба кожи туловища во время лечения наблюдался рост грибов Trichophyton rubrum.

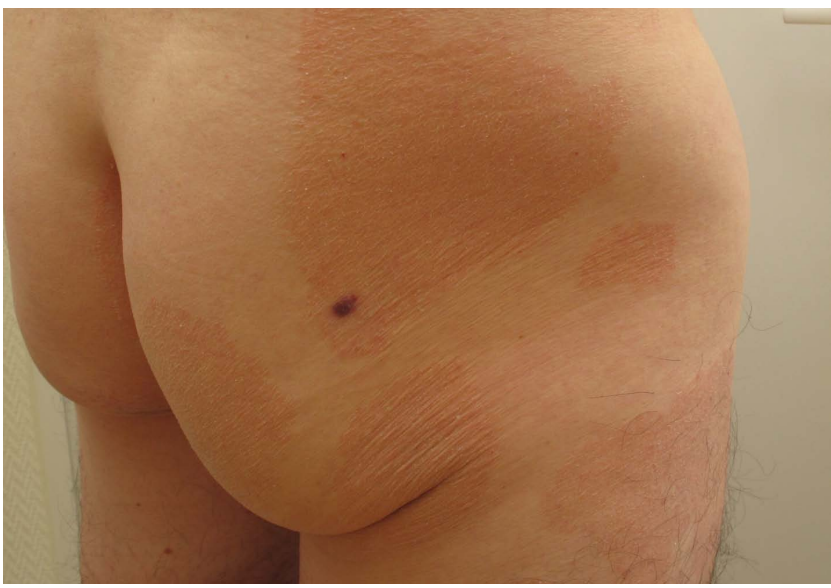

Рис. 2. Состояние кожи правой ягодицы пациента 57 лет, до начала терапии Fig. 2. The condition of the 57-year-old patient's right buttock skin before therapy

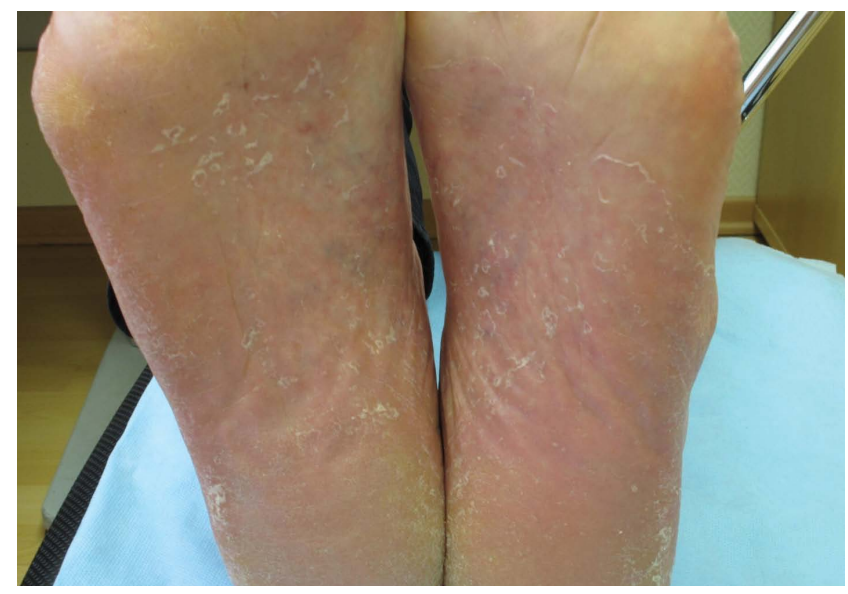

Рис. 4. Состояние кожи подошв пациента 57 лет, до начала терапии Fig. 4. The condition of the 57-year-old patient's soil skin before therapy 
3. При ПЦР-диагностике микозов во время лечения выделены грибы Trichophyton rubrum.

4. Биохимический анализ крови: билирубин, АСТ, АЛТ, щелочная фросфатаза, гамма-глутамин-аминотрансфераза перед началом терапии и во время приема системных противогрибковых препаратов в пределах нормы.

5. Заключение гистологического исследования от 2015 года: выявленные изменения не противоречат клиническому диагнозу - болезнь Девержи.

6. При гистологическом исследовании от 2016 года диагноз - себорейная экзема.

7. Операция по поводу рака левой почки в 1992 году. Заключение нефролога перед началом терапии: противопоказаний для приема системного антимикотика нет.

На основании данных анамнеза, клинической картины и результатов микроскопического исследования соскобов с кожи туловища и ногтевых пластин стоп был установлен диагноз - распространенный микоз гладкой кожи с поражением ногтевых пластин стоп.

Назначено системное и наружное противогрибковое лечение: тербинафин 250 мг по 1 табл. 1 раз в день 3 месяца с самостоятельными 2-3-недельными перерывами, затем по 1 табл. 1 раз в день в течение 2 месяцев и 14-дневным курсом - 3 месяца с медленной положительной динамикой в виде отрастания ногтей стоп на 40 \% площади, сохранением высыпаний на коже туловища и положительными контрольными результатами микроскопического исследования на грибы, в связи с чем рекомендовано поменять антимикотический препарат из другой фрармакологической группы. Пациент принимал итраконазол по схеме пульс-терапии по 2 капсулы 2 раза в день в течение 7 дней, затем 3 недели перерыв, курс № 6 с положительным эффректом в виде отрастания на 2/3 площади здоровых ногтевых пластин стоп, но с сохранением бляшек на неинфильтрированном фоне с шелушением на поверхности в области спины и ягодиц, на фоне приема итраконазола высыпания полностью разрешились, затем появились вновь. По поводу микоза ногтей стоп проводилась наружная противогрибковая терапия до полного их отрастания.

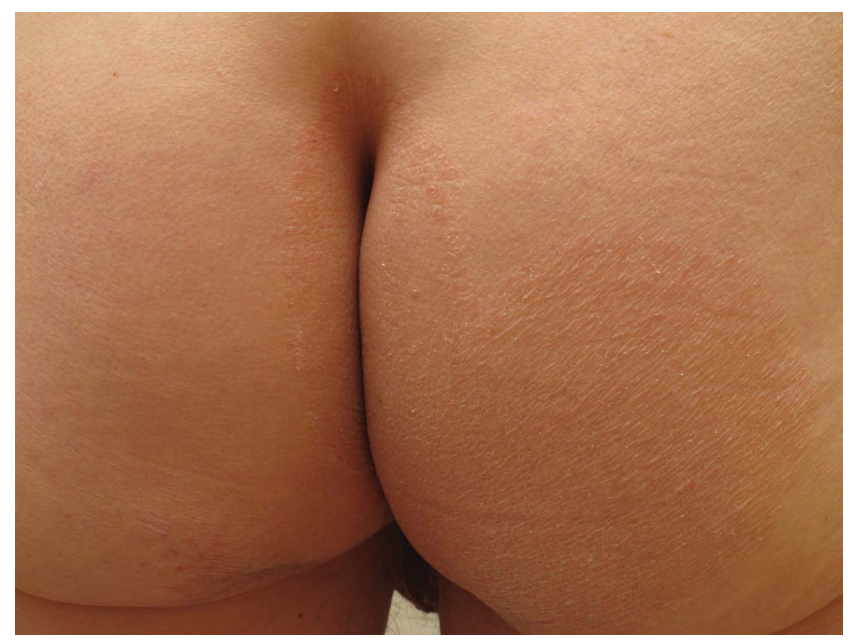

Рис. 5. Состояние кожи ягодиц и межягодичной складки пациента 57 лет, во время противогрибковой терапии

Fig. 5. The condition of the 57-year-old patient's buttock and intergluteal cleft skin during antifungal therapy
При контрольном микроскопическом исследовании в лаборатории ГНЦДК МЗ РФ от 2014 г. в соскобе с кожи туловища мицелий грибов не обнаружен. Поставлен диагноз - себорейный дерматит, назначен фрлюконазол по 150 мг в неделю в течение 1,5 месяца, токофрерол ацетат, наружная противовоспалительная терапия, крем с мочевиной и салициловой кислотой с разрешением высыпаний на коже туловища и ягодиц, которые вновь появились через 4 месяца.

На основании клинической картины, рецидива высыпаний на коже туловища был поставлен клинический диагноз: себорейная экзема, крупнобляшечный парапсориаз, болезнь Девержи, и пациент направлен на гистологическое исследование биоптата кожи ягодиц.

Заключение гистологического исследования от 2015 г.: выявленные изменения не противоречат клиническому диагнозу - болезнь Девержи.

Через 2 месяца при микроскопическом исследовании в лаборатории ГНЦДК МЗ РФ в соскобе с кожи туловища, подошв и ногтей стоп обнаружены мицелий грибов.

Локальный статус: в области спины и правой ягодицы с переходом на межъягодичную складку наблюдаются очаги обильного шелушения, со слабовыраженным валиком по периферии, розового цвета (рис. 5). Изменены 2-й, 3-й ногти правой стопы по гипертрофическому типу, дистально-латеральная форма, с вовлечением матрикса, коричневого цвета. Проведена коррекция вросшего 1-го ногтя левой стопы с помощью коррекционной пластины (рис. 6). На подошвах наблюдается гиперемия и обильное шелушение. Ногтевые пластины кистей не изменены.

Назначили тербинафин по 1 табл. 1 раз в день 4 месяца с разрешением очагов в области спины, отрастанием здоровых ногтей стоп на 1/2 площади, затем после самостоятельного 1,5-месячного перерыва проводилась наружная противогрибковая, антибактериальная и гормональная терапия с ухудшением и положительным анализом на грибы в соскобе с кожи ягодиц, паховых складок и мошонки, потом пациент принимал тербинафин по 1 табл. 1 раз в день -2 месяца и через день - 2 месяца с периодическим появлением

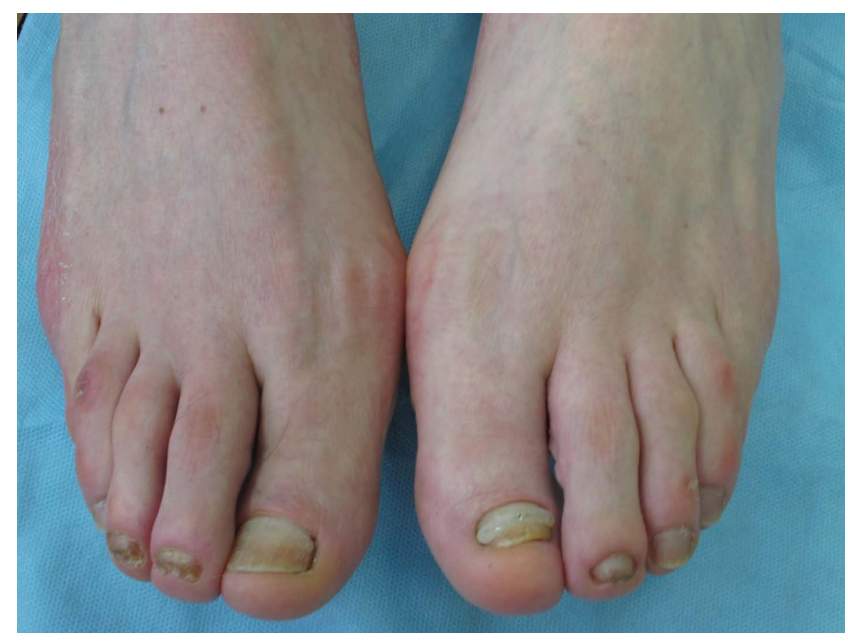

Рис. 6. Состояние ногтей стоп пациента 57 лет, во время противогрибковой терапии Fig. 6. The condition of the 57 -year-old patient's foot nails during antifungal therapy 
высыпаний на коже подошв, правой ягодицы, бедра, паховых складок и мошонки.

Локальный статус: имеются очаги инфильтрации округлых и неправильных фрорм с прерывающимся валиком по периорерии на поверхности шелушение, кожа паховых складок и мошонки гиперемирована со среднепластинчатым шелушением, трещины, умеренный зуд.

На основании клинической картины - сохранение высыпаний на коже туловища на фроне проводимой противогрибковой терапии - был поставлен клинический диагноз: себорейная экзема, лимфома кожи, и пациент направлен на гистологическое исследование биоптата кожи мошонки и бедра.

Гистологическое исследование (с кожи мошонки и бедра) от 2016 г., заключение: данных за лимфому кожи не выявлено, выявленные изменения не противоречат клиническому диагнозу - себорейная экзема.

При контрольном микроскопическом исследовании в лаборатории ГНЦДК МЗ РФ от 2016 г. в соскобе с кожи поясничной области обнаружен мицелий грибов. Наблюдалось ухудшение состояния ногтей стоп. Изменены 1, 3, 5-й ногти левой и 2, 3, 5-й ногти правой стопы по гипертрофическому типу, дистально-латеральная форма, более 1/2 площади, сероватого цвета.

В связи с отсутствием положительной динамики от противогрибковой терапии пациенту рекомендовано провести полимеразную цепную реакцию (ПЦР) диагностику микозов и культуральное исследование с определением чувствительности грибов к системным антимикотикам. При ПЦР-диагностике и культуральном исследовании соскоба кожи туловища выделены грибы Trichophyton rubrum. Определение чувствительности грибов Trichophyton rubrum к системным антимикотикам не проводилось.

Пациенту был назначен итраконазол по схеме пульс-терапии по 2 капсулы 2 раза в день после еды в течение 7 дней, с перерывом 3 недели, курс 4 месяца. С учетом зарубежного опыта назначения препарата по интермиттирующей схеме до полного отрастания ногтей пациент продолжал прием итраконазола по 100 мг в неделю - 6,5 месяца с положительным эффректом

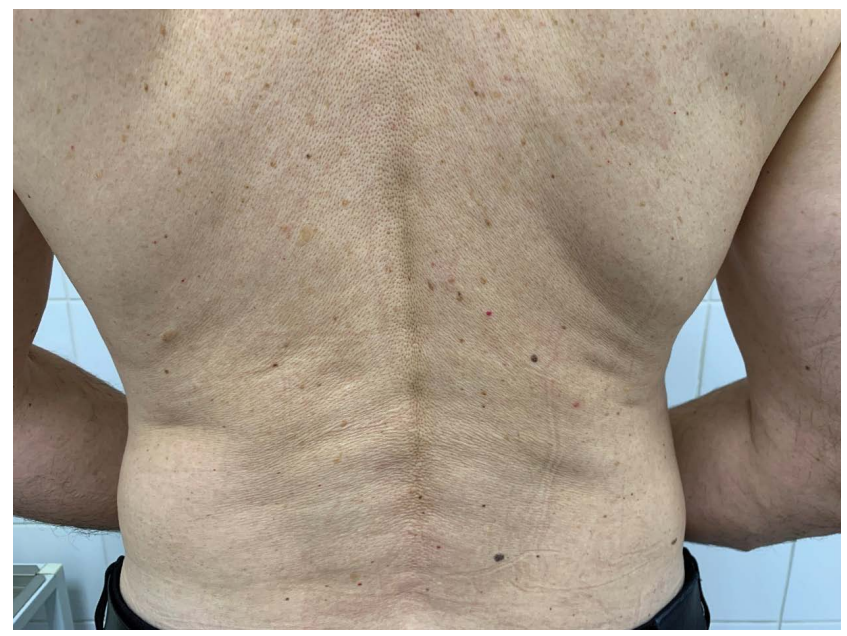

Рис. 7. Состояние кожи спины пациента 57 лет, клиническое и микологическое излечение

Fig. 7. The condition of the 57-year-old patient's back skin, clinical and mycological cure в виде полного отрастания всех ногтей стоп и 3-го ногтя правой стопы на 90 \% площади, с разрешением высыпаний на коже спины, подошв, правой ягодицы и бедра. Через месяц высыпания вновь появились на коже правой ягодицы, бедра и спины. Продолжалась наружная противогрибковая терапия, через месяц на фоне проводимой наружной противогрибковой терапии и травмы ногтей стоп отмечалось ухудшение их состояния.

При контрольном микроскопическом исследовании в лаборатории ГНЦДК МЗ РФ от 2017 г. в соскобе с ногтей стоп, спины и правой ягодицы обнаружен мицелий грибов.

С 2017 по 2019 г. пациент принимал итраконазол по схеме пульс-терапии 1, 2 и 6 курсов, кетоконазол 200 мг по 1 табл. в день - 3 месяца с положительным эфрфректом.

Одновременно с системной противогрибковой терапией проводилась наружная противогрибковая терапия (клотримазол, бифоназол, нафтифин, изоконазол, тербинафин, циклопирокс, аморолфин), отслойки с помощью 10 \% салициловой мази, серно-салициловой мази, регулярные аппаратные обработки ногтей стоп в подологическом кабинете.

Во время лечения пациент проводил дезинфекцию белья, носков, обуви и предметов обихода с помощью современного отечественного дезинфицирующего средства - 2 \% раствора «Самаровки» или методом кипячения в 1-2 \% мыльно-содовом растворе в течение 10-20 минут или в 2-3 \% растворе хозяйственного мыла в течение 5-10 минут, затем проглаживал горячим утюгом во влажном виде, а также применял устройство противогрибковой обработки обуви «Тимсон» [6-10].

На фроне проводимого лечения был отмечен регресс высыпаний на коже спины, ягодиц, правого бедра, стоп, паховых складок и отрастание здоровых ногтей стоп (рис. 7-10).

При контрольном микроскопическом исследовании в лаборатории ГНЦДК МЗ РФ от сентября 2019 г. в соскобе с кожи мошонки, паховых складок, подошвы, ногтей стоп мицелий грибов не обнаружен, с кожи ягодиц и задней поверхности правого бедра обнаружен.

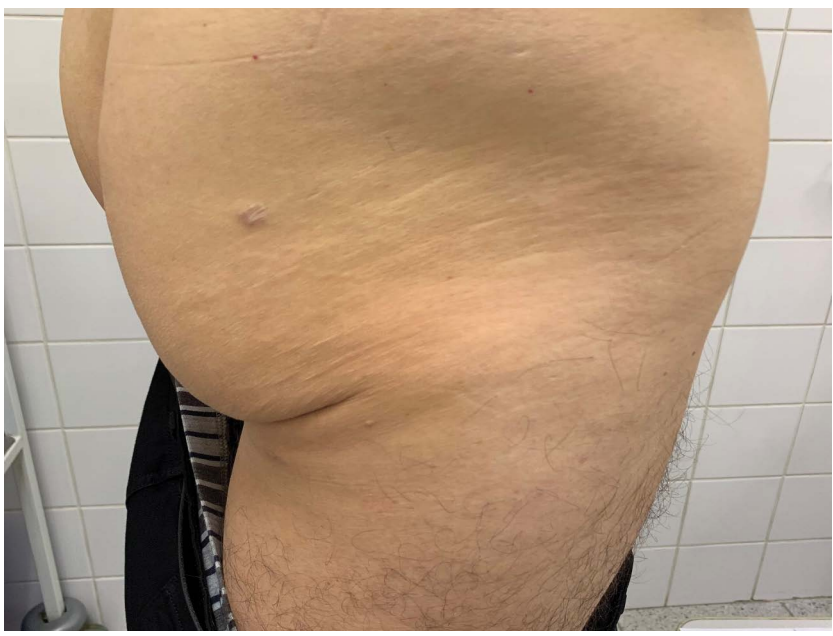

Рис. 8. Состояние кожи правой ягодицы и бедра пациента 57 лет, клиническое и микологическое излечение

Fig. 8. The condition of the 57-year-old patient's right buttock and thigh skin clinical and mycological cure 


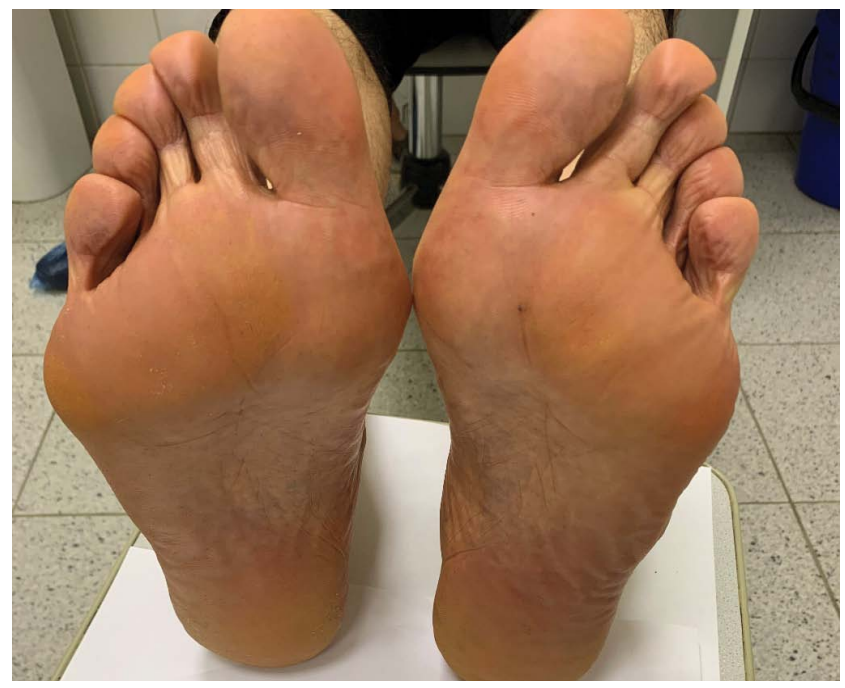

Рис. 9. Состояние кожи подошв пациента 57 лет, клиническое и микологическое излечение

Fig. 9. The condition of the 57-year-old patient's soil skin, clinical and mycological cure

Проводилась наружная противогрибковая терапия 2 раза в день в течение 1 месяца.

При контрольном микроскопическом исследовании в лаборатории ГНЦДК МЗ РФ от октября 2019 г. в соскобе с кожи ягодиц и задней поверхности правого бедра мицелий грибов не обнаружен.

В настоящее время пациент находится на диспансерном наблюдении.

При контрольном микроскопическом исследовании в лаборатории ГНЦДК МЗ РФ от декабря 2019 г. в со-

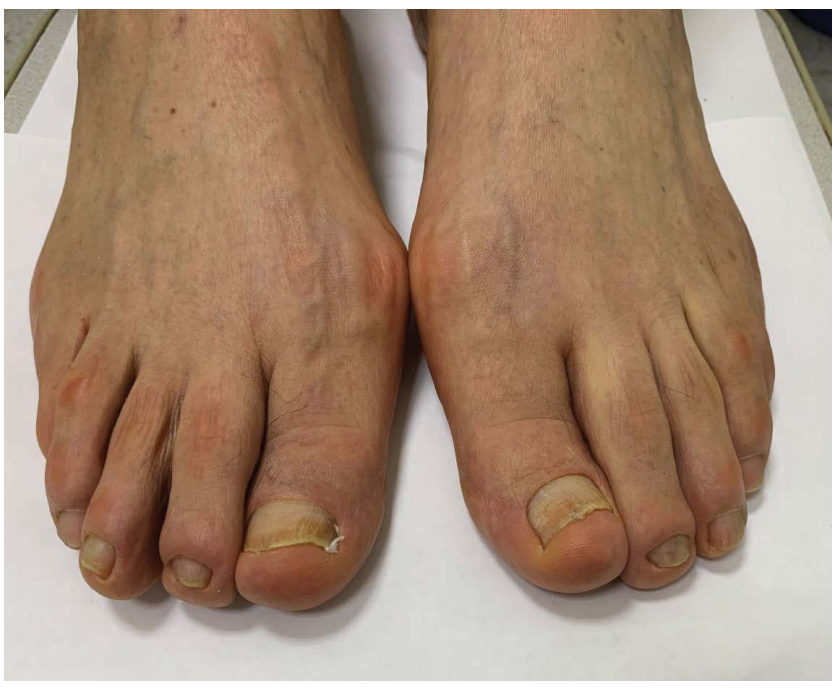

Рис. 10. Состояние ногтей стоп пациента 57 лет, клиническое и микологическое излечение

Fig. 10. The condition of the 57-year-old patient's foot nails, clinical and mycological cure

скобе с ногтей стоп, кожи паховых складок, подошвы и ягодиц мицелий грибов не обнаружен.

\section{Выводы}

Необходимо дальнейшее изучение резистентных форм дерматомикозов к системной антимикотической терапии и проведение дополнительных исследований по определению чувствительности возбудителей к противогрибковым препаратам для выявления устойчивых штаммов грибов.

\section{Литература/References}

1. Budak A., Bogusz B., Tokarczyk M., Trojanowska D. Dermatophytes isolated from superficial fungal infections in Krakow, Poland, between 1995 and 2010. Mycoses. 2013;6(4):422-428.

2. Sarifakioglu E., Seckin D., Demirbilek, Can F. In vitro antifungal susceptibility patterns of dermatophyte strains causing tinea unguium. Clin Exp Dermatol. 2007 Nov;32(6):675-679. Epub 2007 Aug 22.

3. Gupta A. K., Kohli Y. Evaluation of in vitro resistance in patients with onychomycosis who fail antifungal therapy. Dermatology. 2003;207(4):375-380.

4. Mendez-Tovar L. J., Manzano-Gayosso P., Velasquez-Hernandes V. et al. Resistance to azolic compounds in clinical Trichophyton spp. strains. Rev Iberoam Micol. 2007 Dec 31;24(4):320-322.

5. Bradley M. C., Leidich S., Isham N., Elewski B. E., Ghannoum M. A. Antifungal susceptibilities and genetic relatedness of serial Tri- chophyton rubrum isolates from patients with onychomycosis of the toenail. Mycoses. 1999;42 Suppl 2:105-110.

6. Kozhichkina N. V. Mold onychomycosis: a diagnostic algorithm and prevention. Medical technology for dermatologist, mycologist and laboratory-doctor. Moscow, 2001. P. 9-10.

7. Fedorova L. S., Stepanova Z. V., Kozhichkina N. V. New methods for the shoes desinfection. Disinfection Journal. 2005;3:39-42.

8. Stepanova Z. V. Prevention mycosis. Moscow, 2008. P. 12-15.

9. Sheklakov N. D., Leshenko V. M. Methodical recommendation for clinics, diagnostic, treatment and prevention mycosis foot. Moscow, 1979. P. 14-15.

10. Kashkin P. N. Dermatomycosis. Guide for doctors. Leningrad: Meditsina, 1967. P. 223-227.

\section{Информация об авторе}

Наталия Владимировна Кожичкина - к.м.Н., младший научный сотрудник отдела дерматологии Государственного научного центра дерматовенерологии и косметологии Министерства здравоохранения Российской Федерации; e-mail: konat1@yandex.ru

\section{Information about the author}

Natalia V. Kozhichkina - Cand. Sci. (Med.), Junior Researcher, Department of Dermatology, State Research Center of Dermatovenereology and Cosmetology, Ministry of Health of the Russian Federation; e-mail: konat1@yandex.ru 